\title{
ANALISIS PENGARUH INFLASI DAN PRODUK DOMESTIK REGIONAL BRUTO (PDRB) TERHADAP PENDAPATAN ASLI DAERAH DI KOTA MANADO
}

\author{
Indra Randy Weley, Anderson G. Kumenaung, Jacline I. Sumual \\ Fakultas Ekonomi Dan Bisnis Program Magister Ilmu Ekonomi \\ Universitas Sam Ratulangi
}

\begin{abstract}
ABSTRAK
Pembangunan daerah sebagai bagian integral dari pembangunan nasional. Ketergantungan dana pemerintah daerah pada pemerintah pusat mewujudkan juga keterbatasan kemampuan pemerintah mengakumulasi Pendapatan Asli Daerah (PAD). Untuk meningkatkan pelaksanaan pembangunan dana pemberian pelayanan masyarakat serta peningkatan pertumbuhan ekonomi di daerah diperlukan penyediaan sumber-sumber dan pendapatan asli daerah yang hasilnya memadai. Inflasi merupakan salah satu indikator ekonomi penting yang dapat memberikan informasi mengenai perkembangan harga barang dan jasa yang dibayar oleh konsumen. Pendapatan Asli Daerah (PAD) Kota Manado tiap tahunnya mengalami peningkatan seiring dengan meningkatnya PDRB yang disertai dengan fluktuasi Inflasi akibat pertumbuhan ekonomi yang terjadi di Kota Manado. Penelitian ini untuk mengetahui pengaruh inflasi dan PDRB terhadap Pendapatan Asli di Kota Manado. Data yang digunakan adalah data sekunder dimana metode analisis regresi menjadi alat analisis yang digunakan. Hasil penelitian, PDRB dan inflasi mempengaruhi Pendapatan Asli Daerah Kota Manado.
\end{abstract}

kata kunci : PDRB, Inflasi, PAD

\begin{abstract}
Regional development as an integral part of national development. The dependence of local government funds to realize the central government also limited the government's ability to accumulate revenue (PAD). To improve the implementation of development funds provision of public services as well as increased economic growth in the region required the provision of resources and local revenues that result adequate. Inflation is one of the important economic indicators that can provide information on the development of prices of goods and services paid by consumers. Revenue (PAD) Manado City each year has increased along with the increasing GDP is accompanied by fluctuations in inflation due to the economic growth that occurred in the city of Manado. This study was to determine the effect of inflation and GDP to real income in the city of Manado. The data used is secondary data which the regression analysis method into a tool of analysis used. The results of the study, GDP and inflation affect the original income of Manado.
\end{abstract}

Key words: GDP, Inflation, PAD kata kunci: PDRB, Inflasi, PAD 


\section{Latar Belakang}

\section{PENDAHULUAN}

Pembangunan ekonomi adalah usaha-usaha untuk meningkatkan taraf hidup suatu bangsa yang sesuai dengan tujuan pembangunan nasional yaitu mencapai suatu masyarakat yang adil dan makmur, materiil dan spiritual berdasarkan Pancasila dan UUD 1945 yang seringkali diukur dengan tinggi rendahnya pendapatan riil perkapita. Tujuan pembangunan ekonomi disamping untuk meningkatkan pendapatan riil juga untuk meningkatkan produktivitas. Produktivitas adalah kemampuan menghasilkan, pada umumnya dapat dikatakan bahwa tingkat output pada suatu saat tertentu oleh tersedianya manusia, tingkat teknologi, keadaan pasar dan kerangka kehidupan ekonomi (sistem perekonomian) serta sikap dari output itu sendiri.

Pembangunan daerah sebagai bagian integral dari pembangunan nasional dilaksanakan berdasarkan prinsip otonomi daerah dalam pengaturan sumber daya nasional yang memberikan kesempatan bagi peningkatan demokrasi dan kinerja daerah untuk meningkatkan kesejahteraan masyarakat menuju masyarakat madani yang bebas korupsi, kolusi dan nepotisme. Pembangunan daerah yang dilaksanakan sangat diharapkan agar tidak hanya bersifat di daerah perkotan tetapi harus mencakup keseluruhan suatu daerah dari tingkat kabupaten, kecamatan dan desa. Selama ini pembangunan yang berjalan hanya terjadi di pusat saja sedangkan pembangunan di daerah hampir tidak ada. Hal ini disebabkan dana yang sebenarnya untuk pembangunan daerah untuk hampir seluruhnya disetor ke pusat sehingga terjadi ketidakseimbangan pembangunan. Dengan demikian tergantung pada pusat dalam pembiayan pembangunan.

Pembangunan ekonomi suatu daerah pada dasarnya merupakan suatu proses pertumbuhan ekonomi yang seharusnya bertumpu pada kemampuan perekonomian daerah yang bersangkutan sama seperti pembangunan ekonomi suatu negara yang harus bertumpu pada perekonomian dalam negeri sendiri. Meningkatnya kebutuhan pembangunan dengan sendirinya meningkatkan kebutuhan pembiayaan pembangunan. Di satu pihak diperhadapkan dengan keterbatasan sumber daya alam dan sumber daya manusia. Sebagaimana Jhingan (1994:53) mengatakan bahwa pembangunan ekonomi suatu daerah haruslah secara tepat memenuhi kebutuhan dan pada kondisi serta kemampuan daerah tersebut.

Pembangunan daerah merupakan semua kegiatan pembangunan baik yang termasuk maupun yang tidak termasuk urusan rumah tangga daerah yang meliputi berbagai sumber pembiayaan baik dari pemerintah maupun dari masyarakat. Sumber pembiayaan tersebut terdiri dari PAD, dana perimbangan, pinjaman daerah dan lain-lain penerimaan yang sah. Hal ini memberi peluang lebih banyak kepada daerah menggali sumber-sumber penerimaan daerah.

Dalam era otonomi daerah saat ini dengan kewenangan yang lebih luas dalam melaksanakan pembangunan maka dibutuhkan data yang lebih terfokus pada pembangunan di daerah tersebut. Indonesia adalah salah satu negara di kawasan Asia yang mengalami krisis mata uang yang kemudian menjadi suatu krisis ekonomi yang besar. Dimana nilai rupiah mengalami kemerosotan yang sangat drastis terhadap dollar. Yang dapat mengakibatkan pendapatan perkapita turun yang sangat berpengaruh terhadap jalannya roda perekonomian nasional dikarenakan pemerintah melakukan suatu kebijaksanaan pengetatan likuiditas. Akibatnya banyak investor yang menanamkan modalnya dinegara lain karena biaya kredit di Indonesia sangat mahal. Padahal kita tahu bersama bahwa suku bunga yang tinggi akan mengurangi investasi.

Akibat merosotnya nilai rupiah terhadap dollar yang friar biasa, banyak perusahaanperusahaan penanggung hutang yang kesulitan melunasi hutanghutangnya dan tidak melakukan 
hedging atas hutangnya-hutangnya. Tujuan memelihara nilai rupiah mempunyai dua dimensi : domestik dan luar negeri. Kestabilan nilai rupiah dari dua sudut domestik menuntut inflasi rendah atau bahkan nol, sedangkan keluar negeri berarti berbagai sistem perhitungan nilai tukar yang ada, terlihat inflasi menjadi salah satu dari beberapa variabel penentu nilai tukar dan mata uang asing.

Kondisi perekonomian suatu wilayah dapat dilihat dari Produk Domestik Regional Bruto (PDRB) wilayah tersebut. Sebagai salah satu indikator makro ekonomi, pada dasarnya PDRB merupakan jumlah nilai tambah yang timbul dari seluruh sektor perekonomian disutu wilayah tertentu, atau merupakan jumlah nilai barang dan jasa akhir yang dihasilkan oleh seluruh unit ekonomi. Dalam perhitungan PDRB digunakan dua macam harga, yaitu PDRB Atas Dasar Harga Berlaku dan PDRB Atas Dasar Konstan. PDRB atas dasar harga berlaku menggambarkan nilai tambah barang dan jasa yang dihitung dengan menggunakan harga yang berlaku setiap tahun, sedangkan PDRB atas dasar harga konstan dihitung dengan menggunakan harga pada satu tahun tertentu. PDRB atas dasar harga berlaku dapat digunakan untuk melihat struktur ekonomi, sedangkan PDRB atas dasar harga konstan untuk melihat pertumbunhan ekonomi.

Manado merupakan bagian dari negara Indonesia dan merupakan salah satu daerah di Sulawesi Utara, tentunya merasa akibat-akibat yang ditimbulkan inflasi apalagi saat ini dimana pembangunan daerah merupakan integral pembangunan nasional yang dilaksanakan berdarkan prinsip otonomi daerah dan pengaturan sumber daya nasional yang memberikan kesempatan bagi peningkatan demokrasi dan kinerja daerah. Penyelenggaraan pemerintah daerah sebagai sub sistem pemerintah negara dimaksud untuk meningkatkan daya guna dan hasil guna penyelenggaraan pemerintah dan pelayanan masyarakat. Dengan adanya otonomi daerah ini, Manado hams mampu mengatasi masalah-masalah ekonomi yang dialaminya termasuk masalah inflasi yang dapat mengakibatkan merosotnya pendapatan riil masyarakat yang tentunya akan mempengaruhi pendapatan asli daerah di Kota Manado sendiri

\section{Perumusan Masalah}

Berdasarkan latar belakang di atas maka dirumuskan masalah sebagai berikut :

" Bagaimana pengaruh inflasi dan Produk Domestik Regional Bruto (PDRB) terhadap Pendapatan Asli Daerah di Kota Manado"

\section{Tujuan Penelitian}

Penelitian ini bertujuan untuk mengetahui pengaruh inflasi dan PDRB terhadap pendapatan asli Daerah di Kota Manado".

\section{Manfaat Penelitian}

Penelitian ini diharapkan dapat bermanfaat :

1. Sebagai bahan informasi/bahan masukkan pemerintah Kota Manado, khususnya bagi instansi-instansi dan dinas-dinas yang terkait dalam menetapkan kebijaksanaan yang berkaitan dengan tingkat inflasi dan pendapatan asli daerah.

2. Sebagai bahan referensi dan perbandingan bagi para peneliti lain yang nantinya ingin meneliti lebih lanjut tentang penelitian ini 


\section{Pengertian Pendapatan}

\section{LANDASAN TEORI}

Pendapatan adalah arus uang atau barang yang menguntungkan bagi seseorang, kelompok, individu, sebuah perusahaan atau perekonomian selam beberapa waktu. Pendapatan bisa berasal dan penjualan jasa-jasa produktif (seperti : gaji, bunga, keuntungan, uang, sewa, pendapatan nasional).

Pendapatan Nasional adalah nilai seluruh barang-barang dan jasa-jasa yang diproduksikan oleh suatu negara dalam waktu satu tahun tertentu. Pendapatan Nasional dapat dihitung dengan tiga cara, yakni Produk Nasional Bruto (PNB), Produk Domestik Bruto (PDB) dan Pendapatan Nasional. (Sukirno 1993 : 55)

Definisi lain dan pendapatan adalah jumlah penghasilan yang diperoleh dan hasil pekerjaan dan biasanya pendapatan seseorang dihitung setiap tahun atau setiap bulan. Dengan demikian pendapatan merupakan gambaran terhadap posisi ekonomi keluarga dan dalam masyarakat.

\section{Macam-macam Pendapatan}

\section{Pendapatan dari gaji dan upah.}

Gaji dan upah adalah balas jasa terhadap kesediaan menjadi tenaga kerja. Besar gaji atau upah seseorang secara teoritis sangat tergantung dari produktifitasnya. Ada beberapa faktor yang mempengaruhi produktifitas, sebagai berikut :

- $\quad$ Keahlian (Skill)

- Mutu Modal Manusia (Human Capital)

- Kondisi Kerja (Working Condition)

\section{Pendapatan dari Aset Produktif}

Aset produktif adalah asset yang memberikan pemasukan atas balas jasa pengunaannya. Ada dua (2) kelompok aset produktif, pertama, asset fmansial (financial assets), seperti deposito yang menghasilkan pendapatan bunga, saham yang menghasilkan defiden dan keuntungan atas modal (capital gain) bila diperjualbelikan. Kedua, asset buka financial (real assets), seperti rumah yang memberikan penghasilan sewa.

\section{Pendapatan dari pemerintah (transfer payment)}

Pendapatan dari pemerintah atau penerimaan transfer payment adalah pendapatan yang diterima bukan sebagai balas jasa atau input yang diberikan. Misalnya dalam bentuk tunj angan penghasilan bagi para penganggur (unemployment compensation), jaminan social bagi orangorang miskin dan berpendapatan rendah (social security).

\section{Pengertian Pendapatan Asli Daerah (PAD)}

PAD atau Pendapatan Asli Daerah menurut Undang-Undang No.34 tahun 2004 tentang perimbangan keuangan pemerintah pusat dan daerah adalah penerimaan yang diperoleh daerah dari sumber-sumber dalam wilayahnya sendiri yang dipungut berdasarkan Peraturan Daerah sesuai Perundang-undangan yang berlaku. Sebagai sumber pendapatan daerah yang penting dan strategis dalam kaitannya dalam pelaksanaan otonomi daerah maka diupayakan adanya peningkatan PAD yang murni sehingga menjadi salah satu tolak ukur dalam melaksanakan pembangunan di lingkungan sendiri.

\section{Faktor-faktor yang mempengaruhi Pendapatan Asli Daerah (PAD)}

- Inflasi

- $\quad$ Produk Domestik Regional Bruto (PDRB) 
- Jumlah Penduduk

\section{Inflasi}

\section{Pengertian Inflasi}

Inflasi adalah suatu keadaan yang mengindikasikan semakin melemahnya daya beli yang diikuti dengan semakin merosotnya nilai rill (instrinsik) mata uang suatu negara. (Tajul Khalwaty, 2000: 5).

\section{Teori-teori Inflasi}

\section{1) Teori Kuantitas}

Teori ini adalah teori yang paling tua mengenai inflasi. Teori ini menyeroti peranan dalam proses inflasi dari (a) jumlah uang yang beredar dan (b) psikologi/harapan masyarakat akan kenaikan harga-harga (expectation).

2) Teori Klasik

Teori ini berpendapat bahwa tingkat harga terutama ditentukan oleh jumlah uang beredar, yang dapat dijelaskan melalui hubungan antara nilai uang dengan jumlah uang, serta nilai uang dan harga.

3) Teori Keynes

Teori Keynes mengenai inflasi didasarkan atas teori makronya. Menurut teori ini, inflasi terjadi karena suatu masyarakat ingin hidup sesuatu diluar batas kemampuan ekonominya Proses inflasi menurut pandangan ini tidak lain adalah proses perebutan bagian rejeki diantara kelompok-kelompok sosial yang menginginkan bagian yang lebih besar dan yang biasa disediakan oleh masyarakat itu sendiri

4) Teori Strukturalis

Teori strukturalis adalah teori inflasi jangka panjang yang menyeroti sebab-sebab inflasi yang berasal dari kekuatan struktur ekonomi. Khususnya ketegaran supply bahan makanan dan barang-barang ekspor.

\section{Produk Domestik Regional Bruto (PDRB)}

Menurut BPS (2007 : 2) Produk Domestik Regional Bruto (PDRB) adalah merupakan jumlah nilai tambah yang timbul dan seluruh sektor perekonomian di suatu wilayah tertentu, atau merupakan jumlah nilai dan barang jasa akhir yang dihasilkan oleh seluruh unit ekonomi.

PDRB dapat diartikan sebagai nilai barang-barang dan jasa-jasa yang diproduksikan didalam negara tersebut. Jadi ini dapat diartikan bahwa PDRB adalah nilai barang-barang dan jasa-jasa yang diproduksikan dalam suatu daerah tertentu dalam satu tahun tersebut. (Sukirno, 2006: 33).

\section{Hipotesis}

Berdasarkan latar belakang dan landasan teori maka yang menjadi hipotesis dalam penelitian ini adalah : "Diduga bahwa Inflasi dan Produk Domestik Regional Bruto (PDRB) mempengaruhi Pendapatan Asli Daerah di Kota Manado".

\section{Data dan Sumber Data}

\section{METODE PENELITIAN}

Data yang digunakan dalam penelitian ini adalah data sekunder yang diperoleh langsung dari instansi-instansi yang terkait, dalam hal ini Badan Pusat Statistik (BPS) Kota Manado, 
BAPPEDA Kota Manado dan Dinas Pendapatan Pengelolaan Keuangan dan Aset Daerah (DPPKAD) di Kota Manado, dengan jenis data adalah Inflasi, PDRB dan PAD.

\section{Metode Pengumpulan Data}

Karena data yang digunakan merupakan data sekunder, maka metode pengumpulan data dengan cara mengumpulkan langsung data yang diolah instansi yang terkait dari Badan Pusat Statistik (BPS) Kota Manado, BAPPEDA Kota Manado, dan Dinas Pendapatan Pengelolaan Keuangan dan Aset Daerah (DPPKAD) Kota Manado.

\section{Metode Analisis}

1) Analisis Tabel

Analisis tabel ini digunakan untuk melihat bagaimanakah pengaruh Inflasi dan PDRB terhadap pendapatan asli daerah di kota Manado.

2) Analisis Regresi Berganda

Analisis ini dipakai untuk melihat variabel Inflasi $\left(\mathrm{X}_{1}\right)$ dan variabel PDRB $\left(\mathrm{X}_{2}\right)$ terhdapa variabel PAD (Y) di kota Manado.

Model dasar yang digunakan dapat dispesifikasikan sebagai berikut :

$Y=\beta_{0}+\beta_{1} X_{1}+\beta_{2} X_{2}+e$

Dengan anggapan persamaan diatas bentuknya non linear maka model persamaan diatas di transformasikan ke dalam log sehingga diperoleh model persamaan linear sebagai berikut :

$\log Y=\log \beta_{0}+\beta_{1} \log X_{1}+\beta_{2} \log X_{2}+e$

Dimana :

$\mathrm{Y}$ = variabel yang menunjukkan jumlah pendapatan asli daerah (variabel dependent)

$\mathrm{X}_{1}=$ variabel inflasi (variabel independen)

$\mathrm{X}_{2}=$ variabel PDRB (variabel (independen)

$\beta_{0}=$ intercept

$\beta_{1}+\beta_{2}=$ Koefisien regresi sekaligus elastisitass

$\mathrm{e}($ epsilon $)=$ variabel pengganggu

Untuk mencari nilai $\beta_{0}, \beta_{1}, \beta_{2}$ maka dipergunakan rumus statistik yang dinamakan metode kuadrat terkecil (ordinary least square $=$ OLS), yaitu dengan meminimumkan jumlah kesalahan pengganggu .

Maka diperoleh rumus : $\beta_{0}=Y-\beta_{1} X_{1}+\beta_{2} X_{2}$

$$
\begin{aligned}
& \beta_{1}=\frac{\left(\Sigma \mathrm{YX}_{1}\right)\left(\Sigma \mathrm{YX}_{2}^{2}\right)-\left(\Sigma \mathrm{YX}_{2}\right)\left(\Sigma \mathrm{YX}_{1} \mathrm{X}_{2}\right)}{\left(\Sigma \mathrm{X}_{1}^{2}\right)\left(\Sigma \mathrm{X}_{2}^{2}\right)-\left(\Sigma \mathrm{X}_{1} \mathrm{X}_{2}\right)^{2}} \\
& \beta_{3}=\frac{\left(\Sigma \mathrm{YX}_{3}\right)\left(\Sigma \mathrm{X}_{2}^{2}\right)-\left(\Sigma \mathrm{YX}_{2}\right)\left(\Sigma \mathrm{X}_{2} \mathrm{X}_{3}\right)}{\left(\Sigma \mathrm{X}_{1}^{2}\right)\left(\Sigma \mathrm{YX}_{2}^{2}\right)-\left(\Sigma \mathrm{X}_{1} \mathrm{X}_{2}\right)^{2}}
\end{aligned}
$$


$\mathrm{D}=\left(\Sigma \mathrm{X}_{2}^{2}\right)\left(\Sigma \mathrm{X}_{3}^{2}\right)\left(\Sigma \mathrm{X}_{2} \mathrm{X}_{3}\right)^{2}$

$\mathrm{D}=$ Denominator

Untuk mengitung berapa sumbangan atau proporsi variabel ilnflasi dan PDRB $\left(\mathrm{X}_{1}\right.$ dan $\left.\mathrm{X}_{2}\right)$ terhadap variasi naik turunnya jumlah pendapatan asli daerah $(\mathrm{Y})$ digunakan rumus koefisien determinasi regresi berganda $\left(\mathrm{R}^{2}\right)$, yaitu sebagai berikut :

$$
\mathrm{R}^{2}=\frac{\beta_{1} \Sigma Y X_{1}+\beta_{2} \Sigma X_{2}}{\Sigma Y^{2}} \quad \text { dimana } 0 \leq R^{2} \leq 1
$$

Untuk mengetahui keeratan hubungan atau korelasi inflasi dan PDRB dengan jumlah pendapatan asli daerah, yang digunakan korelasi (R) yang merupakan akar dari koefisien determiasi bergands atau $R=\sqrt{R^{2}}$.

Apabila koefisien korelasi (R) bertanda positif, maka Infalsi dan PDRB mempunyai hubungan positif dengan jumlah pendapatan asli daerah atau hubungan langsung antara $X_{1}$ : $\mathrm{X}_{2}$ dengan $\mathrm{Y}$.

Khusus untuk $\mathrm{R}=+1$ maka dapat dikatakan terdapat hubungan positif sempurna. Namun dalam $R=-1$ maka hubungan itu adalah negatif sempurna antara $X_{1}: X_{2}$ dan $Y$.

Untuk mengetahui kesalahan baku atau standar errornya digunakan rumus :

$$
\begin{aligned}
S \beta_{1} & =\delta \sqrt{\frac{\Sigma X_{2}^{2}}{D}} \\
S \beta_{2} & =\delta \sqrt{\frac{\Sigma X_{1}^{2}}{D}} \\
\delta & =\sqrt{\frac{\Sigma e^{2}}{n-k}}=\sqrt{\frac{\Sigma y^{2}-\beta_{1} \Sigma y x_{1}-\beta_{2} \Sigma y x_{2}}{n-k}} \\
\delta & =\text { Standar error of estimate }
\end{aligned}
$$

Untuk menguji hipotesis digunakan dua cars pengujian :

1. Pengujian hipotesis terhadap parameter pendugaan secara parsial (secara sendiri sendiri) untuk mengetahui ada tidaknya pengaruh terhadap variable tidak bebas secara individual maka digunakan uji t, yang dapat dirumuskan sebagai berikut :

$$
t_{i}=\frac{\beta_{i}}{S \beta_{1}}, i=1,2 \ldots . .
$$

Kemudian dibandingkan dengan nilai yang ada di tabel $t \lambda(n-k)$, dimana $: t_{\text {hitung }} \leq t_{\text {tabe }} \lambda(n-k)$ maka 
hipotesis diterima.

Artinya tidak ada pengaruh antara variabel dependent (jumlah pendapatan asli daerah) terhadap variabel independent (Inflasi dan PDRB).

$\mathrm{t}_{\text {hitung }} \geq \mathrm{t}_{\text {tabel }} \lambda(\mathrm{n}-\mathrm{k})$ maka hipotesis ditolak.

Artinya ada pengaruh antara variabel dependent (jumlah pendapatan asli daerah) terhadap variabel independent (Inflasi dan PDRB).

1. Pengujian Hipotesis scara menyeluruh atau secara bersama-sama guna untuk mengetahui ada tidaknya pengaruh variabel bebas ini terhadap variabel tidak bebas, maka digunakan kriteria uji $\mathrm{F}(\mathrm{F}$ test criteria) dengan rumus sebagai berikut :

Dimana apabila :

$$
\mathbf{F}=\frac{\left.\boldsymbol{\beta}^{\mathbf{1}} \sum \mathbf{X}+\boldsymbol{\beta}_{2} \sum \mathbf{X} \mathbf{S}_{2}\right) / \mathbf{k}-\mathbf{1}}{\sum \mathbf{e}^{2} / \mathbf{n}-\mathbf{k}}
$$

$$
\mathrm{F}_{\mathrm{h}} \quad \geq \mathrm{F}_{\mathrm{t}_{\mathrm{i}}} \quad \lambda(\mathrm{n}-\mathrm{k}, \mathrm{k}-1) \text { maka hipotesis diterima }
$$

Artinya tidak ada hubungan atau pengaruh antara $\mathrm{X}_{1}$ terhadap $\mathrm{Y}$ dan $\mathrm{X}_{2}$ terhadap $\mathrm{Y}$.

$$
\mathrm{F}_{\mathrm{h}} \quad \geq \mathrm{F}_{\mathrm{ti}_{\mathrm{i}}} \quad \lambda(\mathrm{n}-\mathrm{k}, \mathrm{k}-1) \text { maka hipotesis Ditolak }
$$

Artinya ada hubungan atau pengaruh antara X1 terhadap Y dan X2 terhadap Y.

\section{HASIL PENELITIAN DAN PEMBAHASAN}

Untuk menganalisa pengaruh Inflasi $\left(\mathrm{X}_{\mathrm{i}}\right)$ dan PDRB (X2) terhadap Pendapatan Asli Daerah (Y) di Kota Manado, maka digunakan analisis regresi berganda. Dari hasil analisis regresi berganda diperoleh hasil sebagai berikut:

\begin{tabular}{llll|}
\hline $\mathrm{Y}$ & $=-1,858532641$ & $+0,073 \times 1^{*}+2,017 \times 2^{* * *}$ \\
$\mathrm{Sb}$ & $=$ & $(0,027)$ & $(0,867)$ \\
thit & & $(2,633)$ & $(2,324)$ \\
$\mathrm{R}^{2}$ & $=0,90$ & $\mathrm{R}=0,95$ & $\mathrm{~F}=33,743^{* *}$ \\
\hline
\end{tabular}

\section{Ket :*) signifikan pada tingkat a0,025**) signifikan pada tingkat 0,01}

Hasil analisis menunjukkan secara parsial Inflasi di Kota Manado bertanda positif (+), artinya bahwa apabila inflasi mengalami kenaikan, maka jumlah pendapatan asli daerah di Kota Manado akan meningkat. Hal ini terjadi karena peningkatan nilai PAD disebabkan oleh meningkatnya nilai dan harga barang dan jasa yang memberikan kontribusi terhadap peningkatan jumlah PAD di kota Manado.

Hasil analisis menunjukkan bahwa variabel inflasi (Xi) berpengaruh terhadap pendapatan asli daerah $(\mathrm{Y})$ yang ditunjukkan oleh nilai koefisien regresi sebesar 0,073 hal ini berarti apabila inflasi meningkat sebesar $1 \%$ akan menyebabkan pendapatan asli daerah meningkat sebesar $0,073 \%$, dengan asumsi citeris paribus (faktor-faktor lain dianggap tetap). 
Hasil analisis menunjukkan secara parsial Produk Domestik Regional Bruto (PDRB) juga memiliki tanda positif (+), artinya bahwa apabila PDRB meningkat maka jumlah pendapatan asli daerah akan meningkat.

Hasil analisis menunjukkan bahwa variabel PDRB (X2) memiliki pengaruh terhadap pendapatan asli daerah (Y) yang ditunjukkan dengan nilai koefisien regresi sebesar 2,017 hal ini berarti apabila PDRB meningkat sebesar $1 \%$ akan menyebabkan pendapatan asli daerah meningkat sebesar 2,017 dengan asumsi citeris paribus (faktor-faktor lain dianggap tetap).

Uji t digunakan untuk mengetahui pengaruh variabel bebas Inflasi $\left(\mathrm{X}_{\mathrm{i}}\right)$ dan PDRB $\left(\mathrm{X}_{2}\right)$ terhadap variabel tidak bebas pendapatan asli daerah $(\mathrm{Y})$, yang dilakukan dengan membandingkan antara nilai thit ${ }_{\text {ung }}$ dengan nilai $t_{\mathrm{ta}} \mathrm{b}_{\mathrm{e}} \mathrm{i}$ pada tingkat $\mathrm{a}=0,025$

Hasil uji t dengan menggunakan program Microsoft Excel, menunjukkan bahwa nilai thi $i_{\text {tung }}$ pada variabel Inflasi $(X 1)$ sebesar 2,633 $>t_{u}$ be

2,306 yang signifikan pada tingkat $\mathrm{a}=0,025$ Ho ditolak. Dengan demikian, variabel inflasi memiliki pengaruh terhadap pendapatan asli daerah di Kota Manado.

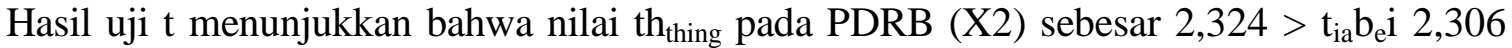
pada tingkat $\mathrm{a}=0,025$. Ho diterima. Dengan demikian, Produk Domestik Regional Bruto (PDRB) memiliki pengaruh terhadap pendapatan asli daerah di Kota Manado.

Hasil analisis menunjukkan pengaruh Inflasi dan PDRB terhadap pendapatan asli daerah dengan nilai koefisien determinasi $\left(R^{2}\right)$ sebesar 0,90 . Hal ini berarti besarnya sumbangan atau proporsi variabel Inflasi (X1) dan PDRB (X2) terhadap naik turunnya pendapatan asli daerah (Y) di Kota Manado adalah sebesar 90\%, sedangkan sisanya $10 \%$ dijelaskan oleh faktorfaktor lain yang dimasukkan dalam model.

Hasil analisis menunjukkan nilai koefisien korelasi $(\mathrm{R})$ sebesar 0,95 . Hal ini berarti Inflasi dan PDRB memiliki hubungan yang sangat erat terhadap pendapatan asli daerah sebesar 90\%. Nilai R ini juga menunjukkan bahwa Inflasi dan PDRB memiliki korelasi yag kuat terhadap pendapatan aslidaerah. Sehingga bila terjadi perubahan pada kedua variabel tersebut maka akan mempengaruhi pendapatan asli daerah.

Hasil perhitungan standar error terhadap variasi Inflasi (Xi) yaitu sebesar 0,027 artinya kemungkinan kesalahan atas penerimaan variabel Inflasi sebagai variabel yang mempengaruhi pendapatan asli daerah (Y) adalah sebesar 0,027. Sedangkan untuk PDRB (X2) standar error adalah sebesar 0,867 artinya kemungkinan kesalahan atas penerimaan PDRB sebagai variabel yang mempengaruhi pendapatan asli daerah (Y) adalah sebesar 0,867.

Pengujian terakhir yaitu untuk melihat pengaruh variabel-variabel bebas (Inflasi dan PDRB) terhadap variable terikat (Pendapatan asli daerah) dengan membandingkan antara $F_{\text {hitung }}$ dengan Ft 1, berdasarkan pengujian nilai Fhitung sebesar 33,743 $>F_{\text {tabel }} 19,25$ hasil ini menunjukkan dalam taraf nyata a 0,01 . Secara bersama-sama atau serentak variabel Inflasi (Xi) dan PDRB (X2) mempunyai pengaruh terhadap Pendapatan Asli Daerah di Kota Manado.

\section{Pembahasan}

Dengan demikian maka hipotesis yang menyatakan bahwa variabel Inflasi (Xi) dan PDRB (X2) secara bersama-sama berpengaruh terhadap Pendapatan Asli Daerah dapat diterima atau Ho ditolak. 


\section{Kesimpulan}

\section{KESIMPULAN DAN SARAN}

Berdasarkan hasil analisa dari penelitian ini, maka ditarik beberapa kesimpulan sebagai berikut :

1. Hasil analisis menunjukkan secara parsial Inflasi di Kota Manado bertanda positif (+), artinya bahwa apabila inflasi mengalami kenaikan, maka jumlah Pendapatan Asli Daerah di Kota Manado akan meningkat, dengan nilai koefisien regresi sebesar 0,073 yang signifikan pada tingkat $\mathrm{a}=0,025$

2. Hasil analisis menunjukkan secara parsial Produk Domestik Regional Bruto (PDRB) juga memiliki tanda positif (+), artinya bahwa apabila PDRB meningkat maka jumlah pendapatan asli daerah akan meningkat 2,017 yang signifikan pada a =0,025.

3. Besarnya sumbangan atau proporsi variabel Inflasi (X1) dan PDRB (X2) terhadap naik turunnya pendapatan asli daerah $(\mathrm{Y})$ ditunjukkan oleh nilai koefisien determinasi $\left(\mathrm{R}^{2}\right)$ sebesar $90 \%$ sedangkan sisanya $10 \%$ dijelaskan oleh faktor-faktor lain.

4. Hubungan antara Inflasi dan PDRB dengan Pendapatan Asli Daerah adalah sangat erat, hal ini ditunjukkan oleh nilai koefisien korelasi (R) sebesar 95\%.

5. Secara menyeluruh Inflasi dan PDRB bersama-sama mempengaruhi Pendapatan Asli Daerah di Kota Manado dengan ditunjukkan oleh nilai $F_{\text {hitung }}$ sebesar 33,743 yang lebih besar dan nilai $F_{\text {table }}$ sebesar 19,25 yang signifikan pada tingkat $a=0,01$.

\section{Saran}

Dan hasil kesimpulan yang telah dikemukakan terlebih dahulu, maka perlu di sarankan bagi pemerintah daerah agar lebih memperhatikan dan meningkatkan kinerja sektor riil pemerintah daerah agar mampu menghadapi masalah-masalah ekonomi seperti inflasi apalagi dalam menghadapi otonomi daerah, yang diharapkan mampu untuk mengendalikan dan menstabilkan tingkat inflasi yang ada di daerah. Karena inflasi itu berpengaruh positif terhadap PAD maka pemerintah Kota Manado perlu menjaga kestabilan tingkat inflasi agar daya beli masyarakat dapat dipelihara. Oleh karena PDRB juga mempengaruhi PAD maka pemerintah daerah perlu menciptakan sumber-sumber ekonomi untuk meningkatkan pertumbuhan PDRB agar PAD dapat mampu ditingkatkan di masa akan datang.

\section{DAFTAR PUSTAKA}

Badan Pusat Statistik. 2007. Manado Dalam Angka, Kota Manado.

Khalwaty Tajul. 2000. "Inflasi Dan Solusinya", PT. Gramedia Pustaka Utama, Jakarta.

Sukirno Sadono. 1997. "Pengantar Teori Ekonomi Makro" Edisi kedua, PT. Raja Grafmdo Persada, Jakarta.

Sukirno Sadono. 2006. "Pengantar Teori Ekonomi Makro" Edisi ke-3, PT. Raja Grafindo Persada, Jakarta.

Undang-Undang No. 34 Tahun 2004. "Tentang Perimbangan Keuangan Pemerintah Pusat dan Daerah" 